\title{
Convection Heat Transfer from Horizontal Rectangular Fin Array having Triangular Perforations
}

\author{
Dilpak Saurabh P..$^{*}$ and S. G.Taji ${ }^{\ddagger}$ \\ ${ }^{\dagger}$ Mechanical Engg.Department, MAEER's MIT College of Engineering, Savitribai Phule Pune University, Pune, India \\ ¥Mechanical Engg. Department, MIT Alandi, Savitribai Phule Pune University, Pune, India
}

Accepted 03 March 2016, Available online 15 March 2016, Special Issue-4 (March 2016)

\begin{abstract}
Fin arrays on horizontal and vertical surfaces are used in variety of engineering applications to dissipate heat to the surroundings. Studies of heat transfer and fluid flow associated with such arrays are therefore of considerable engineering significance. The main controlling variables generally available to the designer are the orientation and the geometry of the fin arrays. In case of short horizontal arrays, it is observed that the air entering symmetrically from both the ends gets heated as it moves towards the centre of the fin channel, as well as it rises due to decrease in density. So, the central portion of the fin becomes ineffective because hot air-stream passes over that part and therefore it does not bring about large heat transfer. The purpose of the present study is to investigate thoroughly the possibility of performance improvement of such arrays by providing triangular perforation at the centre and suggest for selection of optimum notch dimensions and spacing by analysing variety of fin arrangements.
\end{abstract}

Keywords: Fin array, heat transfer study, variety of fin arrangements.

\section{Introduction}

In the study of heat transfer, a fin is a surface that extends from an object to increase the rate of heat transfer to or from the environment by increasing convection. The amount of conduction, convection, or radiation of an object determines the amount of heat it transfers. Increasing the temperature difference between the object and the environment, increasing the convection heat transfer coefficient, or increasing the surface area of the object increases the heat transfer. Sometimes it is not economical or it is not feasible to change the first two options. Adding a fin to an object, however, increases the surface area and can sometimes be an economical solution to heat transfer problems.

Heat removal in an efficient way is necessary in order to maintain reliable operation of devices. The trend in the industry is packing more and more components in a given space. With the trend towards further microminiaturization of electronic packages the thermal design problem is recognized as one of the factors limiting the achievement of higher packaging densities. In the process of microminiaturization, the electric power consumption density increases considerably while the size diminishes. It results in significant increase of power density.

The reliability of equipment is, therefore, becoming more critically dependent on the accuracy of heat

*Corresponding author: Dilpak Saurabh P. transfer analysis, which traces the heat flow from chips to the surroundings. High power dissipation may require new cooling techniques, but because of mechanical simplicity, direct air cooling still remains an attractive method.

The heat generated, in addition to the risk of physically damaging the electronic components, reduces the global performance of the system, so limiting the chance of technical improvements. The major cause of failure is due to temperature rise 55\% as against other factors which accounts $20 \%$ vibration, $19 \%$ humidity and $6 \%$ dust.

There are 2 ways in which cooling can be performed:-

1. Passive cooling i.e. Natural Convection

2. Active cooling i.e. Forced Convection (with help of a fan/blower, etc.).

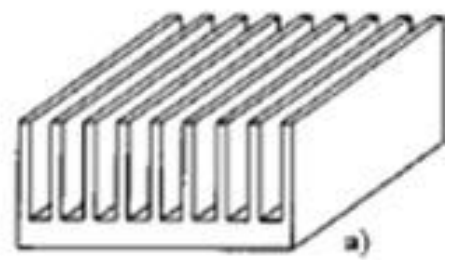

Fig.1 Plate fin array

Fig. 1 shows the plate fin array widely used in cooling applications 


\section{Procedure for Designing}

Three steps in Design procedure

- Thermal modeling and simulation

- Heat sink selection

- Thermal validation

Modes of heat transfer

- Conduction

- Convection

- Radiation

Thermal analysis

- Natural convection

- Forced convection

- Spreading resistance

- Transient analysis

- Cold plate analysis

Design constraints

- Induce approach flow velocity

- Available pressure drop

- Cross sectional geometry of incoming flow

- Amount of required heat dissipation

- Maximum heat sink temperature

- Ambient fluid temperature

- Maximum size of heat sink

- Orientation with respect to gravity

- Appearance \& cost parameters

- Fin height

- Fin length

- Thickness or spacing

- Density / no of fins

- Base plate thickness

- Heat sink material

\section{Experimentation}

An experimental set-up is designed and developed to carry out the investigation on natural and forced convection heat transfer over heated vertical fin arrays.

\subsection{Part One - Natural Convection}

An experimental set up is designed and developed to carry out the experimental study on HRFA with triangular perforated notch. Main objective is to develop an experimental setup as a base for validating the numerical model. Using the validated Numerical model, large data can be generated with different combinations of fin spacing, fin height, and heater load to establish parametric relations. Also, we are trying here to compare the heat transfer patterns between flat a perforated fins.

\subsubsection{Experimental Setup}

Seven arrays with fin spacing 2,3,4,6,8,10 and $12 \mathrm{~mm}$ are tested for plate fin configuration. The length and height of plate fins used is kept constant. Plate fins of height $70 \mathrm{~mm}$, spacers of height $30 \mathrm{~mm}$ and plates of thickness $2 \mathrm{~mm}$ and $3 \mathrm{~mm}$ are used in the assembly. Fin arrays are formed by assembling plate fins and separate spacer pieces and tied together by tie bolts. It is ensured to keep minimum air gap between the plate fins and spacers by proper tightening of the nuts. All fin plates are cut to the same size simultaneously. Fin flats and spacers are clamped together while drilling holes for placing the cartridge heaters which are used for heating the sink, plate fins separated by spacers form fin channels, the fin array configuration. The sides of the array are insulated with bakelite and base is housed in Siporex insulating block in order to ensure required convective heat transfer from fin array and reduce heat loss from bottom and sides. Conduction loss through bottom and sides along with radiation loss is calculated. Copper Constantan thermocouples mounted at appropriate locations are used for temperature measurement. Holes are drilled in fins and plates for housing the thermocouples and direct metal to metal contact between thermocouples and fin/plate surface is ensured. Thermocouples are cut from same spool of wire and the error in the temperature is adjusted with the help of potentiometer in the temperature indicator circuit. Four thermocouples each are used to measure base, fin flat and pin fin temperatures. Thermocouples are also provided in siporex block and Bakelite for heat loss measurement through bottom and sides of the array. Calibrated digital wattmeter is used to measure heater input. Three brass-covered, mica-clad, $12 \mathrm{~mm}$ diameter and $110 \mathrm{~mm}$ long cartridge heaters of $100 \mathrm{~W}$ are used for applying heating load with a stabilized power supply and a dimmer stat.

As the experiment deals with the study of natural convection, proper care is taken to avoid any effect of air movement and outside air entry around the fin array. An enclosure is used in the form of a cubical with a volume of approximately $1 \mathrm{~m} 3$. Three walls of the cubical are of plywood sheets and the front wall is of acrylic sheet. A bottom gap of $0.3 \mathrm{~m}$ from the floor is left and the top of the enclosure is kept open for undisturbed natural convection.

Basic dimensions of the array used for experimentation are $\mathrm{L}=200 \mathrm{~mm}, \mathrm{~B}=124 \mathrm{~mm}, \mathrm{H}=70$ $\mathrm{mm}$. These dimensions are decided by taking into account the convenience of measurement of surface temperatures, input wattage as well as location of thermocouples. Spacers of thickness 2 and $3 \mathrm{~mm}$ and fins of $2 \mathrm{~mm}$ thickness are used.

Insulating siporex block is used to reduce the leakage of heat from bottom and sides of the fin array. In order to account for heat dissipated by radiation, black coating (using the black soot obtained by burning camphor) is used. 


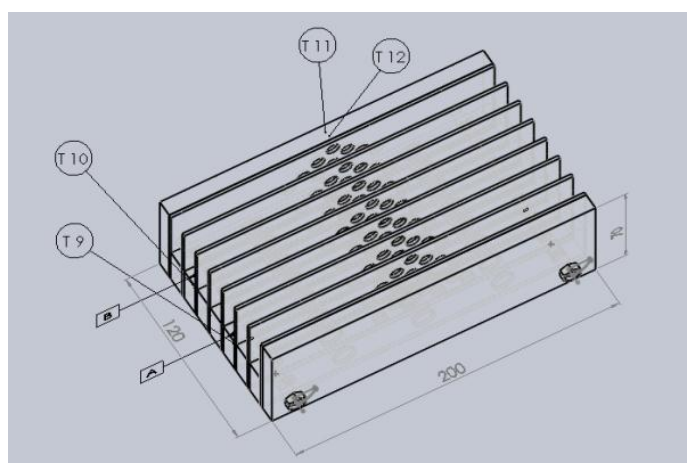

Fig.2 Thermocouple locations for Measurement of array temperature

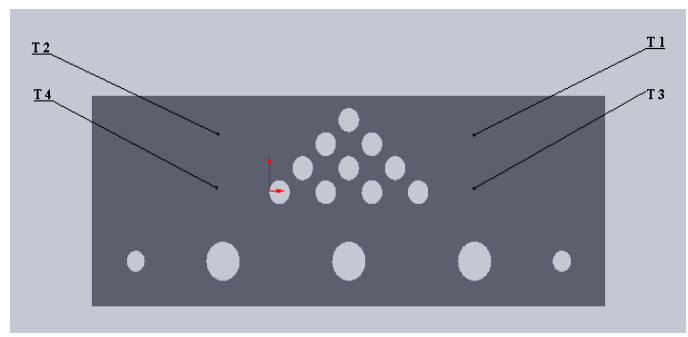

Fig.3 Thermocouple locations for fin A

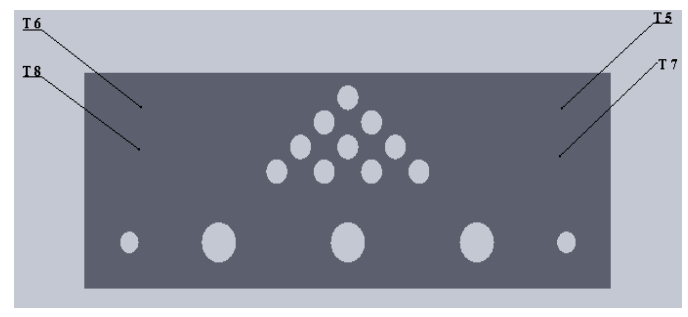

Fig.4 Thermocouple locations for fin B

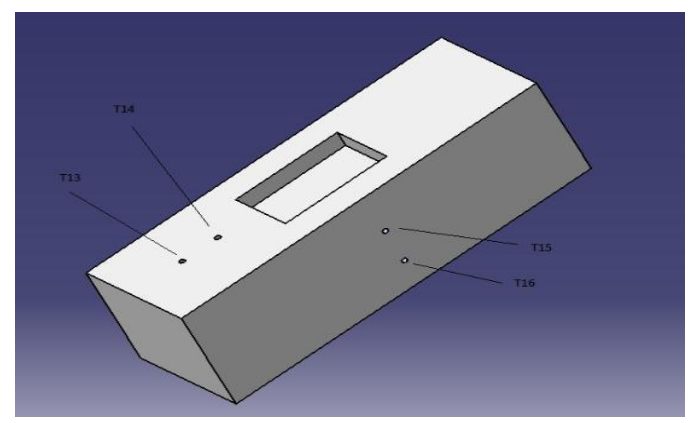

Fig.5Thermocouple locations for measurement of siporex block temperatures for bottom and side loss estimation

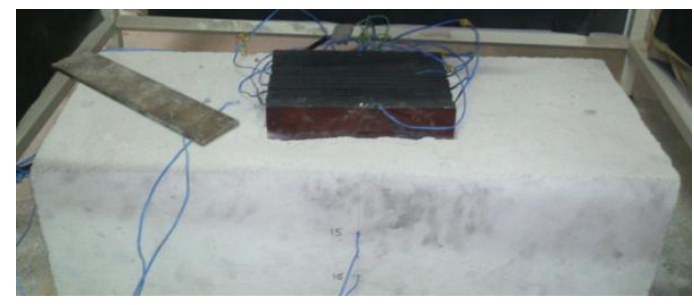

Photo1 Assembly of Fin Array and Siporex Block

\subsubsection{Measurement of Heater Input}

Three cartridge heaters connected in parallel are used for heating the fin array and the heater input is measured with digital wattmeter.

\subsubsection{Temperature Measurement}

Temperatures at different locations are measured with 36 SWG calibrated Copper Constantan thermocouples. Use of 36 gauge enabled minimum disturbance for air flow. Eight thermocouples, mounted at appropriate locations for base and fin for realistic temperature measurement of the fin surface and one for ambient temperature is used for HRFA. Six thermocouples are used for measurement of temperature of Siporex and Bakelite at predefined locations which are used for heat loss calculation. All the thermocouples are of same length and are made from the same spool of wire. Randomly chosen thermocouples are calibrated for the steam point and ice point. Deviation from standard output is taken into consideration while calculating the temperature

\subsubsection{Procedure Of Experimentation}

The following procedure is adopted for carrying out the experimental study.

- The fin array is assembled with spacers and fin flats by using tie bolts and nuts and placing the thermocouples at the appropriate locations.

- Three cartridge heaters are inserted in the three drilled holes. These heaters are connected in parallel in the electrical circuit. Specifications of heaters.

- Assembled array is blackened with camphor and placed in the siporex insulating block.

- Thermocouples T1 to T8 are placed on surface of the fin flat; T9 and T10 are located on the base of the fin channel. Thermocouples T13, T14, T15, and T16 are placed in the Siporex block for measuring conduction loss through sides and bottom of the array and thermocouples T11 and T12 are used for temperature of blackened bakelite for measuring end loss. The assembled array with siporex insulation block is placed at Centre of the enclosure.

- Predetermined heater input is given and kept constant by adjusting the dimmer-stat, which is provided with stabilized voltage input.

- The temperatures of assembled fin array at different locations and ambient temperature are recorded at the time intervals of 1 minute up to steady state condition using data logger. Generally it took 4 hours to attain steady state condition. Steady state is assumed to be reached when the difference in temperatures recorded by a thermocouple is negligible, less than $10 \mathrm{C}$ in half an hour. 


\subsubsection{Assumptions}

The experimental analysis is based on following assumptions.

1. The temperature at any point does not vary with time.

2. The fin material is homogeneous with constant thermal conductivity.

3. The coefficient of heat transfer is constant and uniform over the entire surface of the heat sink.

4. The temperature of the surrounding fluid is uniform.

5. The average temperatures of array recorded after achieving steady state are used for calculating experimental results.

6. The bond resistance to the flow of heat at the base plate of the fin array is neglected.

7. There are no heat sources within the fin itself.

8. The heat flow from the fin is proportional to the temperature difference i.e. excess temperature

\subsection{Part Two - Forced Convection}

\subsubsection{Experimental Set Up}

The general arrangement of experimental set-up is shown in photograph 2.

The set-up comprises of two parts-

\section{1] Test Facility}

It consists of following important parts-

Bell mouth entry, Honeycomb section, Test section, Converging section, PVC pipe, DC fan, Hotwire anemometer.

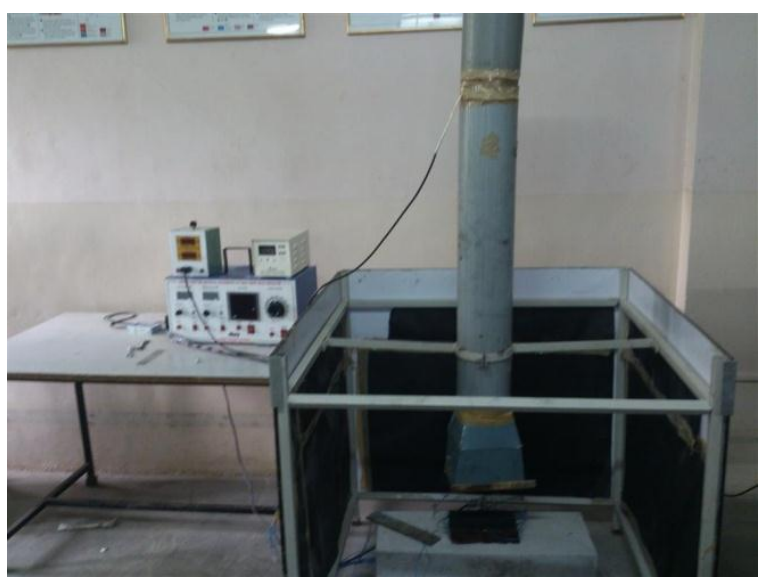

Photo 2 Experimental Setup

The vertical duct is mounted on the stand of sufficient height to get free flow of air. At the suction side bell mouth entry is provided to ensure smooth entry of the air. Followed by is the honeycomb section to get uniform flow throughout the cross section of the duct. In the direction of air flow then comes the settling section helping to develop the flow. At the top of the test section a rod is provided for mounting the fin array module under test. It is followed by a converging section to connect the test section to PVC pipe connected to the DC fan. DC fan generates the desired air flow rate under mixed assisting mode. Test section is connected to suction side of the DC fan under mixed assisting mode. DC fan has specifications:

Type DC fan; Current: 2 Amp; Voltage: 0 to 10 volts; Size: $150 \mathrm{~mm} \times 150 \mathrm{~mm}$

Type: Sisa backward.

Drive: Direct in the direction of air flow.

DC fan is followed by the measuring pipe. At a sufficient distance from the DC fan outlet, orifice meter is provided to measure the flow of air from the pipe. The pressure drop across the orifice plate is measured with the help of U- tube manometer. A flow control valve is provided at the end of measuring pipe, to control the volume flow rate of air.

\section{2] Fin Array Module}

An assembled fin array module is shown in Photo.3. Bakelite plates are kept on both the sides to minimize side losses from the array. Fin flats, spacers and bakelite plates are hold together by means of bolts and nuts. A generalized sketch of a fin flat, spacer and bakelite plate is shown in Figure 5. The dimensions $\mathrm{S}, \mathrm{H}$ and $L$ in the figure indicate the inter fin clear spacing, fin height and fin length. A photograph of the fin array module, with $\mathrm{S}=2 \mathrm{~mm}, \mathrm{H}=40 \mathrm{~mm}$ and $\mathrm{L}=200 \mathrm{~mm}$ is shown in photo 3 .

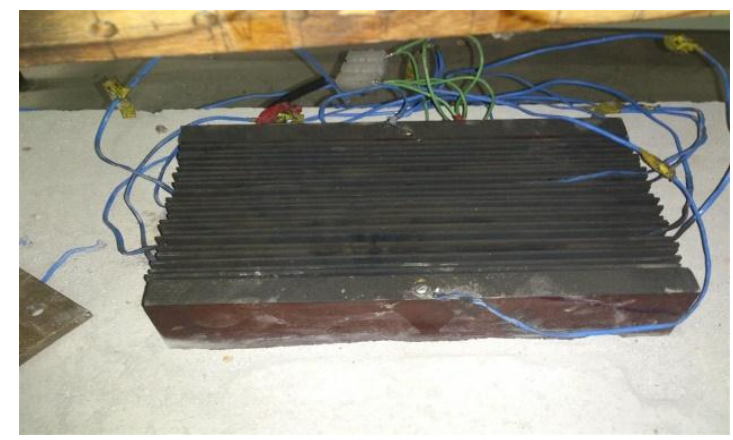

Photo 3 Fin array assembly

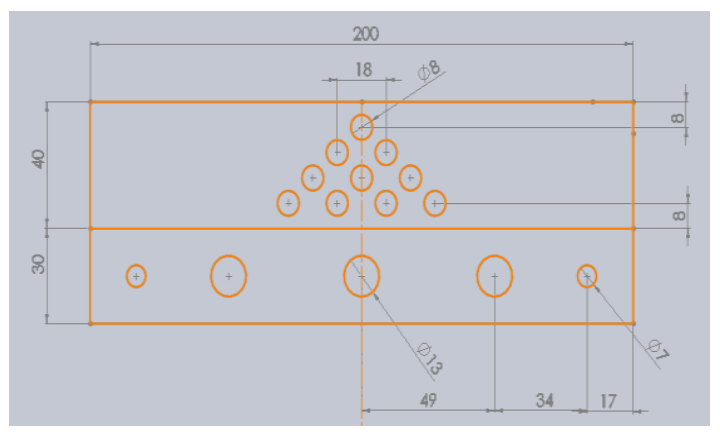

Fig.6 Fin dimensions 
The fin flats are cut out of $2 \mathrm{~mm}$ and $3 \mathrm{~mm}$ thick aluminum sheets, the spacers were cut from aluminum sheets of different dimensions and side plates are cut from bakelite sheet of $12 \mathrm{~mm}$ thickness. A generalized sketch of a fin flat and spacer is shown in the Fig.6.The nuts and bolts holding the module together were made out of $\varnothing 12.7 \mathrm{~mm}$ and $\varnothing 6 \mathrm{~mm}$ M.S. rods. After assembly the module is lamp blackened to behave as black surface.

Various configurations with different values of $S$ and $H$ are tested during the experimentation.

The range of geometric parameters is decided

(1) After reviewing the existing literature on Horizontal rectangular fin arrays.

(2) According to the material availability in the market and feasibility of the configuration assembly.

(3) Based on the capacity of the DC fan and the size of the duct to get the desired $R i$ range under Forced assisting mode.

\subsubsection{Measurement Of The Air}

The desired air velocity through the test section is obtained by controlling the fan speed of the DC fan. It is measured with the help of hot wire anemometer.

Hot Wire Anemometer is a portable air velocity meter is a lightweight instrument that can be used anywhere to measure air velocity. The meter using the snake telescopic probe, applications include the hood velocity, ducts etc.

Feature-

Fast response probe

Air flow volume

Instant / avg 2/3V max flow measurement

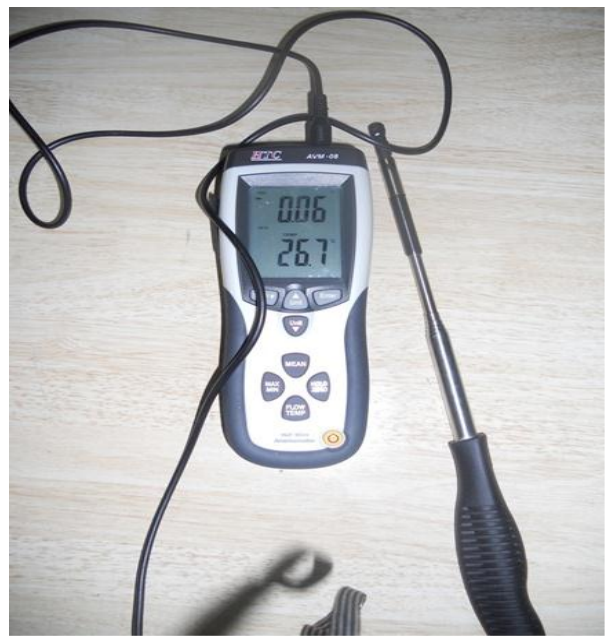

Photo 4 Hot wire anemometer

\section{Specifications}

Display - triple display, 4 digits LCD reading.

Velocity Probe-

Range $0-30 \mathrm{~m} / \mathrm{s}$

Resolution $-0.01 \mathrm{~m} / \mathrm{s}$

Accuracy - +/- 3\% of reading +/- 1\% FS

\subsubsection{Measurement Of The Heater Input}

The rate of heat input for all the 3 heaters is measured with the help of digital voltmeter and ammeter, which are calibrated against standard MECO multi-meter.

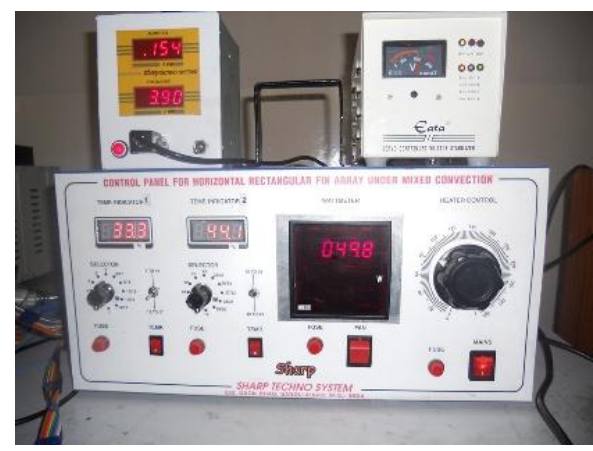

Photo 5 Control panel

Specifications of Wattmeter; voltmeter, ammeter and other instruments are given below

Digital Wattmeter

Size: 96x96; Model Sr. No. Rating: 1250 Watt, Voltage: 250 volts; Current: $5 \mathrm{~A}$

Digital Voltmeter

1. Range 0 to 300 Volt A.C. Resolution 0.1 Volt

2. Digital Ammeter - Range 0 to $2 \mathrm{~A}$, Resolution $0.001 \mathrm{~A}$

3. Dimmer-stat - 0 to $230 \mathrm{~V}, 5 \mathrm{~A}$

4. Digital Temperature Indicator - Range: 0- $300^{\circ} \mathrm{C}$, Resolution $0.1^{\circ} \mathrm{C}$

Photo 5 shows the photograph of the control panel, which includes voltmeter, ammeter, dimmer-stat, selector switch and digital temperature indicator.

\subsubsection{Temperature Measurement}

Temperatures at different locations are measured with the help of 30 SWG copper constantan thermocouples. The thermocouple wires are braided with fiber-glass insulation so as to have both wires as a single unit There are total 6 thermocouples mounted on the fin array surface. Two thermocouples are used for measuring temperature of the air at inlet to the test section and at the exit of the test section. One thermocouple is mounted to measure the duct temperature. Temperature of the side bakelite plates is monitored.

All the thermocouples are made from the same spool of wire. Randomly chosen thermocouple is calibrated using hypsometer for the steam point and thermos flask for ice point. The error in the temperature is adjusted using potentiometer built in the temperature indicator.

\subsubsection{Test Procedure}

Prior to testing, the assembled fin array surfaces are lamp blackened to behave as black surface. Position of 
the duct is adjusted to ensure vertical orientation of the duct. The test procedure adopted for acquiring heat transfer and air flow rate data is as follows:

\subsubsection{Test Procedure under Forced Assisting Mode}

1. Test procedure explained in section 3.4 .1 is followed.

2. DC fan is started with the control valve in the closed position. The main requirement is to create the mixed convection condition with the help of the DC fan.

3. Opening of the control valve is adjusted to obtain the desired air flow rate.

4. Manometer reading is recorded.

5. On reaching of the steady state condition all the observations are recorded.

\section{Experimental Results And Discussion}

The experimental data is used to calculate the heat transfer characteristics. The results are plotted in terms of various heat transfer parameters like average heat transfer coefficient $\left(h_{a}\right)$, base heat transfer coefficient $\left(h_{b}\right)$, average Nusselt number $\left(N u_{a}\right)$, base Nusselt number $\left(N u_{b}\right)$ and Richardson number $(R i)$.

\subsection{Validation of Experiments}

In this chapter validation of experiments is presented under natural and forced convection condition.

\subsubsection{Validation under Forced Convection}

On the same plot the present experimental data is superimposed. It is observed that the present data is confirming the trends obtained by previous investigators.

Figure shows the plot of $h_{a}$ Vs $\Delta T$ for heated vertical plate (Churchill and $\mathrm{Chu}$ correlation). In the same figure $h_{a}$ is also plotted for different fin spacing i.e. $S=2$ to $S=12 \mathrm{~mm}$. Due to the constriction in the fluid flow, at lower spacing $h_{a}$ values are lower as expected, whereas at $\mathrm{S}=12 \mathrm{~mm}$, spacing being wide, $h_{a}$ values approach the vertical flat plate correction values.

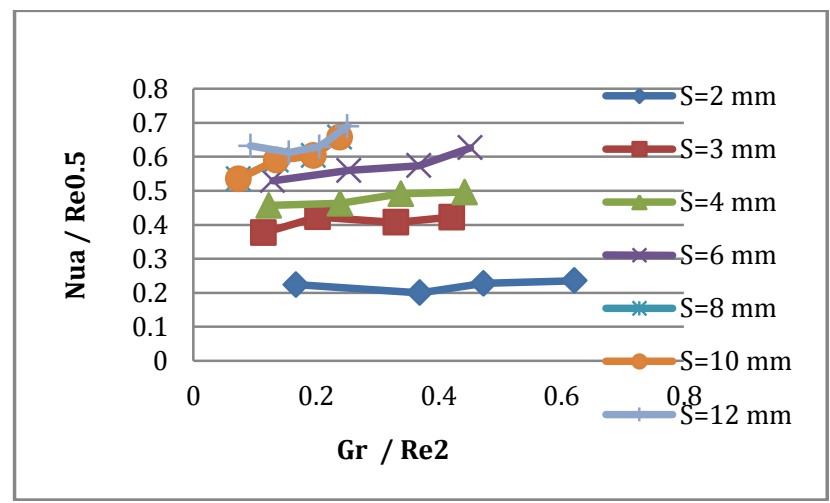

Fig.7Validation under forced convection
Investigators have presented results on forced convection from vertical plates, square and rectangular cavities, vertical parallel plates and other related geometries. Almost no work was reported on forced convection over vertical rectangular fin arrays. Therefore experimental results under forced convection over vertical fin arrays are validated with the results of forced convection over vertical plate under assisting mode.

In the same figure $\mathrm{Nu} / \mathrm{Re} \mathrm{e}^{0.5}$ is also plotted for different fin spacing i.e. $\mathrm{S}=2$ to $12 \mathrm{~mm}$. Due to the constriction in the fluid flow, at lower spacing, $\mathrm{Nu} / \mathrm{Re} e^{0.5}$ values are lower as expected. Whereas at $S=4 \mathrm{~mm}$ values are maximum, as spacing near the optimum region. At $\mathrm{S}=6 \mathrm{~mm} \mathrm{Nu} / \mathrm{Re}^{0.5}$ values reduce due to reduction in surface area. At $S=12 \mathrm{~mm}$ values further reduce and approach the vertical flat plate correlation values, spacing being wide.Results of forced convection heat transfer over vertical fin arrays lie within the cluster of points, presenting results of previous investigators as shown in Figure 11. Present results are in close agreement with previous values. Present experimental results are also compared with heat transfer over a vertical plate, under natural and forced assisting convection mode.

Effect f 1. $\Delta T$ On $h_{a} 2 . R a$ On $N u_{a}$

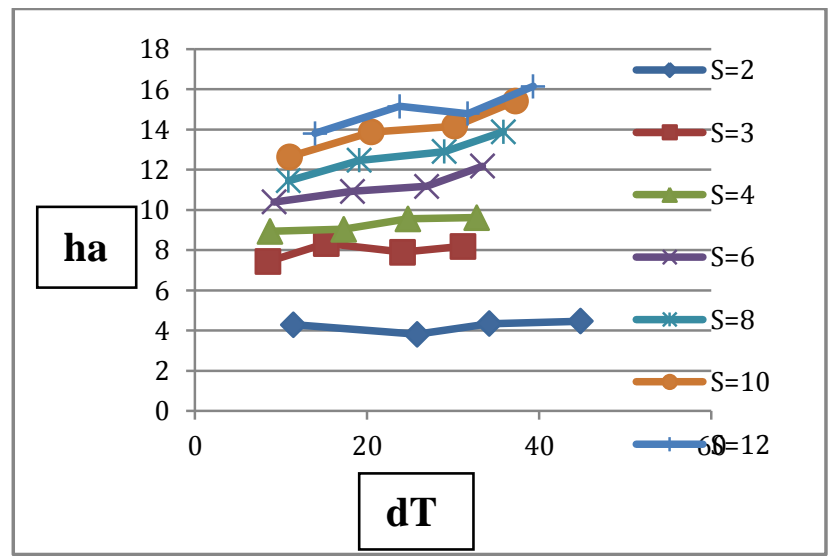

Fig.8 $\Delta \mathrm{T}$ Vs $\mathrm{h}_{\mathrm{a}}\left(\mathrm{W} / \mathrm{m}^{2} \mathrm{k}\right)$

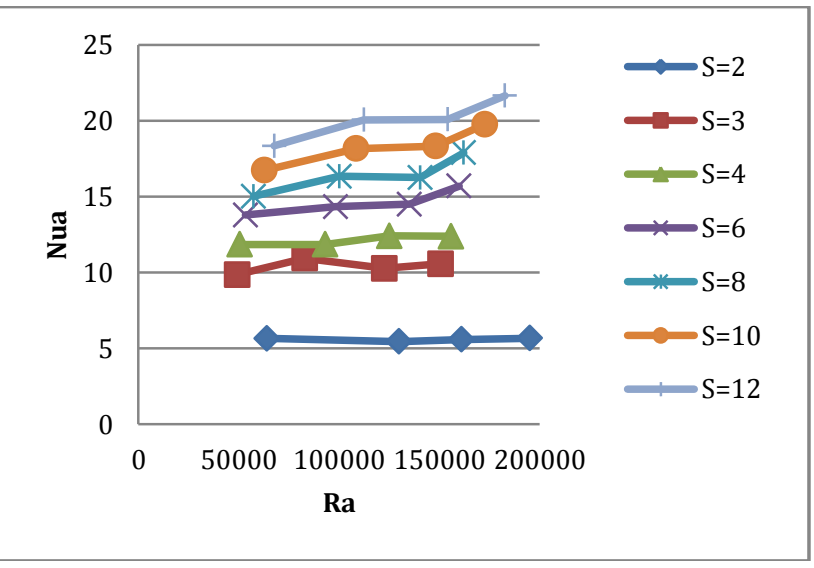

Fig. 9 Ra Vs $\mathrm{Nu}_{\mathrm{a}}$ 


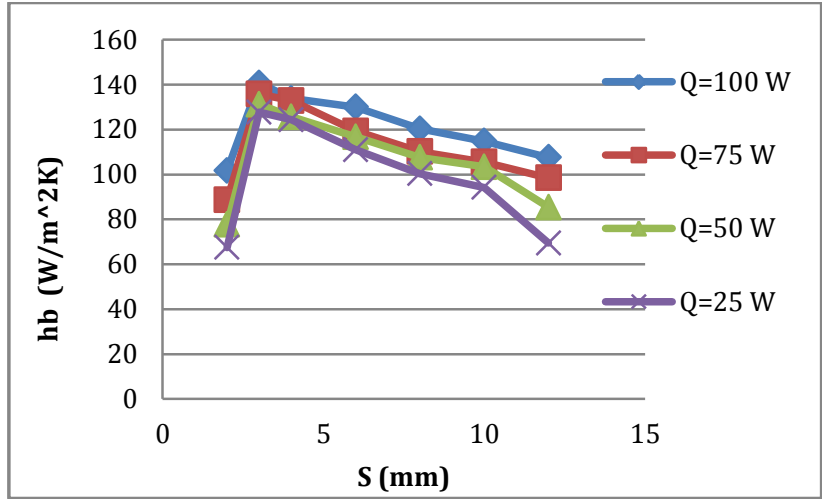

Fig.10 $\mathrm{S}(\mathrm{mm}) \mathrm{Vs}_{\mathrm{b}}\left(\mathrm{W} / \mathrm{m}^{2} \mathrm{k}\right)$

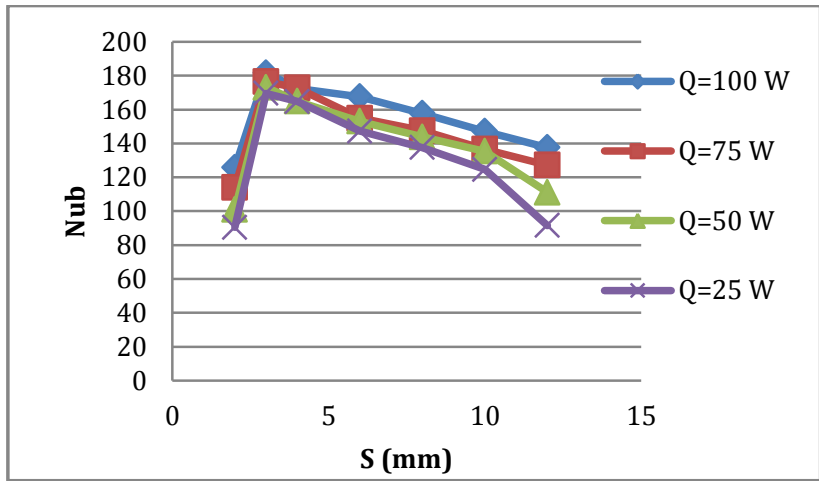

Fig.11 $\mathrm{S}(\mathrm{mm}) \mathrm{Vs} \mathrm{Nu}_{\mathrm{b}}$

Comparing Perforated and Unperforated Fin Arrays

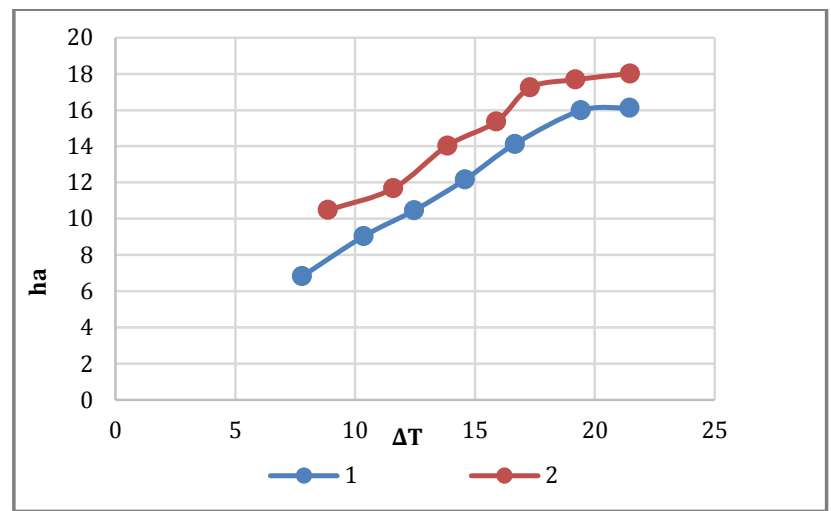

Fig.12(a)

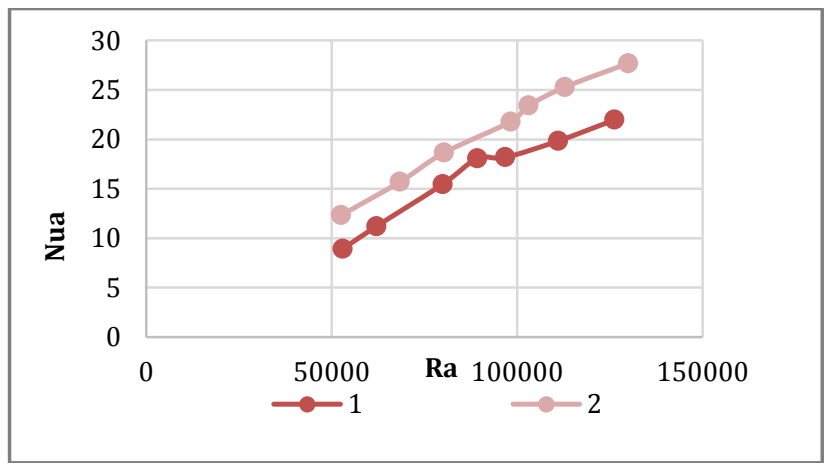

Fig.12(b)

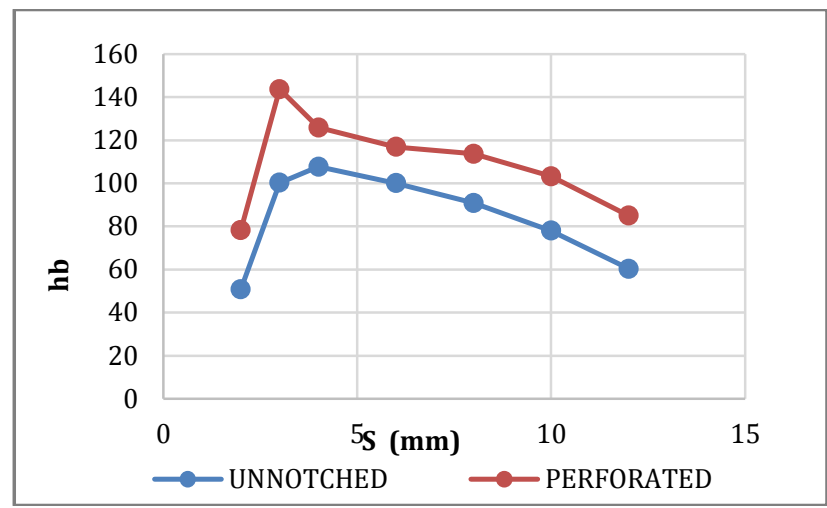

Fig.12(c)

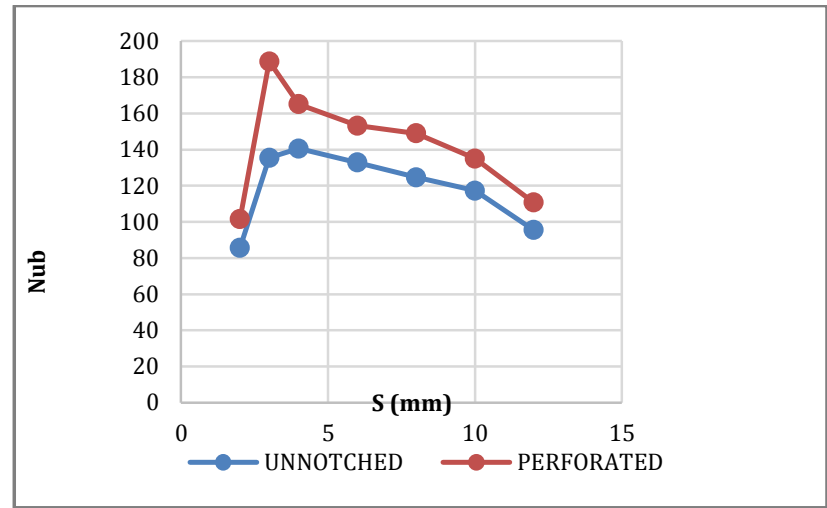

Fig.12(d) Comparison

\section{Conclusions}

In this experimental study, an attempt is made to improve the performance of horizontal rectangular fin array by removing the less effective portion of the fin flat in the form of triangular perforations. It is observed that

1. Total heat flux as well as the heat transfer coefficient increase as the perforations depth increases.

2. As area removed from the fin is compensated at the air entry ends of the fin it provides chance to get greater amount of fresh cold air to come in contact with hot fin surfaces.

3. As the air moves inwards along chimney profile, it gets heated and temperature difference between the fin and entering air decreases.

4. An optimum spacing region obtained in experimental investigations matches closely with the numerical predictions under both natural and forced convection.

5. The optimum spacing region is wider under assisting mode compared with natural convection.

6. At all Ri, forced flow assists natural convection currents and $h_{a}$ values are always higher in assisting mode compared with those under natural convection.

7. Optimum spacing shifts towards lower values with drop in the $R i$. 
8. Base heat transfer coefficient values increase with increase in height.

9. Effect of fin height on optimum spacing region is not significant.

10. When the removed area is added at place where it is more useful for heat transfer, the heat transfer increases and so does the convective heat transfer coefficient. This analysis reveals that the recommended single chimney flow pattern is maintained for the perforated fin arrays.

11. The performance of perforated fin arrays is 20 to $30 \%$ superior to corresponding un-perforated arrays, in terms of average heat transfer coefficient.

\section{Future Scope}

Experimental and numerical studies on forced convection are limited to a few problems only such as vertical plate, parallel plates etc. Keeping in view wide applications of vertical fin arrays, the problem of forced convection over perforated rectangular fin arrays is taken up for the present study. Forced convection from other fin configurations such as horizontal fin arrays may be a worth investigating problem.

So far no work was noticed on opposing mode, where the forced and free convection are of opposite nature. Similarly free and forced convections may be in directions perpendicular to each other. This problem will open a new topic for further research.

\section{References}

Elenbaas W (1942),Heat dissipation of parallel plates by free convection: Physica IX (1) 1-27.

Starner K. E. and Mcmanus H. N., (1963),An experimental investigation of free convection heat transfer from rectangular fin arrays, Journal of Heat Transfer, Trans ASME, series C,85, 273.

Welling J.R. and Wooldridge C.B,(Nov.1965), Free convection heat transfer coefficients from rectangular vertical fins,Journal of Heat Transfer, Trans. ASME, series C, pp $438-444$.

Harahap, F and Mcmanus H. N, (1967), Natural convection heat transfer from horizontal rectangular fin arrays, Journal of Heat Transfer, Trans ASME, series C,89, 32

Jones C. D. and Smith L. F, (1970), Optimum arrangement of rectangular fins on horizontal surfaces for free convention heat transfer, Journal of Heat Transfer, Trans ASME, series C, 92, 6

Mannan K. D, (1970), An experimental investigation of rectangular fins on horizontal surfaces, $P h . D$ Thesis, Ohio State University.

Levy E.K, (1971), Optimum plate spacings for laminar natural convection heat transfer from parallel vertical isothermal flat plates, ASME Journal of Heat Transfer 93 (4) 463-465.

Levy E.K., Eichen P.A., Cintani W.R. and Shaw R.R., (1975), Optimum plate spacings for vertical isothermal flat plates: experimental verification,ASME Journal of Heat Transfer 97 474-476.

Cohen-Bar and Rohsenow W.M., (1984), Thermally optimum spacing of vertical, natural convection cooled, parallel plates, ASME Journal of Heat Transfer 106 116-123.

Sane N.K. and Sukhatme S.P., (1974), "Natural convection heat transfer from horizontal rectangular fin arrays, in: Proc. Of 5th International Heat Transfer Conference, Tokyo, Japan, Vol. 3, NC3.7, pp. 114-118.

Shalaby M.A.I., (1983), Natural convection heat transfer from rectangular fin arrays, Ph.D. Thesis, I.I.T. Mumbai, India

Shalaby M.A.I., Gaitonde U. N. and Sukhatme S. P. (1984), Natural convection heat transfer from rectangular fin arrays, Indian Journal of Technology, 22,321.

Karagiozis A.N, (1991), An investigation of laminar free convection heat transfer from isothermal finned surface, $P h D$ thesis, University of Waterloo. 